\title{
Empirical Research on Fair Value Measurement and Reliability of Accounting Information
}

\author{
Zhu Lv \\ Shanghai University, Shanghai 200444, China. \\ lilylyu@foxmail.com
}

\begin{abstract}
The advantages and disadvantages of fair value measurement are a difficult issue in accounting research. This article empirically tests the impact of fair value measurement on the reliability of accounting information. The research results show that the fair value measurement reduces the reliability of the company's accounting information, which is detrimental to users of accounting information making correct decisions and reducing the quality of accounting information. This study provides some reference for the improvement of relevant criteria and the application of fair value in China.
\end{abstract}

Keywords: Fair value; reliability of accounting information; discretionary accruals.

\section{Introduction}

China had introduced fair value in 1998 and was later misused to manipulate profits, leading to the suspension of the 2001 declaration and reintroduction until 2006. The reason is that fair value measurement involves a large number of judgments, estimates and assumptions in the process of use, and assessment techniques are more difficult to grasp; and the measurement method requires active economic market and enough relevant information, but the actual market environment is complex and information Incomplete. In particular, China's capital market started relatively late and there is still a certain distance from a perfect market environment. However, the introduction and exploration of fair value measurement is an inevitable trend of market economy development. This paper intends to use the relevant data of listed companies in recent years as a basis to analyze the relationship between fair value measurement and the reliability of accounting information, whether the use of fair value measurement will affect the reliability of accounting information. We hope to provide data support for the application of fair value in China and the improvement of China's accounting standards.

\section{Related Literature and Hypotheses}

Regarding the impact of fair value measurement on the quality of accounting information, the existing literature mainly consists of the determination and disclosure of fair value, the pro-cyclical effect of fair value, and the conflict between the true fairness characteristics of fair value accounting and the principle of accounting conservatism. Lang Jun (2015) believes that fair value measurement has great uncertainty, and Sulci (2015) pointed out that this is mainly due to the fact that the determination of fair value is not the result of a real transaction and is virtual. Hu Lingui (2015) believes that because of the lack of clear valuation models, parameter assumptions, and guidelines and specifications of relevant laws and regulations, the operability of fair value is greatly reduced. For example, when Li Kevin (2015) had statistics on the fair value measurement of 1570 listed companies in Shanghai and Shenzhen in 2007 (the data was disclosed in the 2007 annual report), it was found that 630 companies had investment real estate, but Only 18 companies adopted fair value for subsequent measurement, and their measurement methods were also different. In addition, Feng Jibe (2014) constructively proposed that the development level of China's capital market is relatively low, and the relevant conditions are still not perfect, and fair value should be used with caution. Ramona and Watts (2012) and Dec how et al. (2010) believe that due to the lack of verification of fair value results, it will give management some discretion, thus providing opportunities for managers to manipulate financial statements and perform earnings management; Barth et al. (2008) believe that 
because of the many estimations, judgments, and assumptions involved in the use of fair value measurement, the resulting accounting information improves the correlation to a certain extent, but it also reduces reliability accordingly.

Wang Joe (2016) analyzed the changes in the fair value of income and the changes in availablefor-sale financial assets and capital reserves of 14 listed commercial banks in China and found that fair value measurement would amplify current-term profit and capital fluctuations. In addition, the global financial crisis in 2008 is the starting point of this debate. The pro-cyclical effect of fair value measurement is that when the market is booming, the value of assets will rise to be included in income, which will further promote market prosperity and lead to an overvalued asset value; when the market is low, the decline in asset value will be included in profit or loss, further exacerbating the market downturn, causes the value of assets to be underestimated. In this regard, Allen and Carlotta (2006) believe that fair value measurement leads to a prolonged cyclical decline in prices, accelerating price declines during the market downturn, and increasing potential market risks. Some scholars, such as Matson and Shapiro (2008), proposed that they could consider establishing an "emergency plan" for fair value in order to cope with the accounting problems in the economic crisis or enterprise scale adjustment and other periods, and reduce the negative impact of fair value measurement on the economy. In addition, Shan Hong (2011) believes that a high-quality accounting system cannot not only overestimate corporate value, but also cannot underestimate corporate value. However, the requirement of "unpredictable profits, only expected losses" for accounting conservatism will make accounting information reflect it's the actual value is biased.

The fair value has been widely used and promoted since the implementation of the New Accounting Standards for Business Enterprises in 2007, thirteen of the 38 accounting standards require the fair value measurement to be used in varying degrees. At the beginning of 2014, China broke through the fragmented provisions on fair value in the past, clarified and expanded it, issued the No. 39 Accounting Standards for Enterprises to systematically elaborate and regulate it, and committed itself to further expand its influence and establish a theoretical system of fair value measurement. Fair value is the product of social and economic development, and its progress and applicability are obvious, but there are also many problems in its practical application. As shown above, fair value is not based on the products of real transactions, and a large number of judgments and assumptions are involved in the confirmation and measurement process. Especially in the economic environment of our country, it is difficult to obtain relevant information on the use of fair value recognition directly from the market. The certainty and verifiability of information results are greatly affected. That is, it is likely to have an impact on the reliability of accounting information and even make the fair value a way of profit manipulation. For example, Wang Marlin (2016) believes that China's technology for estimating fair value is still not perfect, and the subjective randomness of enterprises is relatively large. Wang Gooding (2016) believes that China's market information is confusing and fragmented. It is more difficult and costly to grasp market conditions. Based on the above analysis, this paper proposes the following hypothesis: Fair value measurement will reduce the reliability of accounting information.

\section{Research Design}

\subsection{Sample Selection}

Since the fair value has been widely used since 2007, this article selected Chinese A-share listed companies from 2007 to 2014 as research samples. After eliminating companies with financial and related data missing, a total of 8,783 samples were obtained. The relevant data comes from CSMAR. At the same time, this article uses the Winsor method to handle the outliers at the $1 \%$ and $99 \%$ levels.

\subsection{Model Design and Variable Definition}

Drawing on relevant research results, build the model as follows: 
Among them, DA is the absolute value of control accruals; FV indicates whether there is an amount in "Change in Fair Value". If there is an amount, FV value is taken as 1; SIZE is the size of the company, which is represented by the natural logarithm of the company's total assets; LEV is the debt to asset ratio; PE is the static price-earnings ratio; DUA means whether the current chairman and general manager of the company are the same person. If the same person, the DUA value is 1; AUD means whether the accounting firm hired by the company in the current period is the top four in the world; the meaning of HE is the degree of concentration of the shares, it is expressed by whether the proportion of the largest shareholder of the listed company is greater than 50\%; OP meaning for the current audit opinion; The use of this model to test the research hypothesis is mainly to investigate whether $\alpha 1$ is significantly greater than 0 , that is, whether the use of fair value will significantly increase handling accruals, and whether it will significantly reduce the reliability of accounting information.

\section{Empirical Results}

\subsection{Descriptive Statistics}

The maximum and minimum values of DA indicate that there are widespread profit manipulations and impaired accounting information quality in listed companies; In the case of further research on $\mathrm{FV}$, it was found that 2,770 of the 8,833 sample companies had "financial value changes and gains and losses". To some extent, it shows that the use of fair value measurement in China is not very extensive. The analysis of variance of the sample companies divided into two groups according to whether or not the fair value measurement was used yielded an F value of 5.14, with a significance of 0.023 , indicating that the difference between the two groups of data was mainly due to the use of fair value. This result initially supports the research hypothesis.

Table 1. Descriptive statistics

\begin{tabular}{cclllll}
\hline Variables & $\mathbf{N}$ & Mean & \multicolumn{1}{c}{ STD } & $\mathbf{5 0 \%}$ & \multicolumn{1}{c}{ Max } & Min \\
\hline DA & 8783 & 0.083 & 0.108 & 0.050 & 0.698 & 0.001 \\
FV & 8783 & 0.315 & 0.465 & 0.000 & 1.000 & 0.000 \\
SIZE & 8783 & 22.103 & 1.375 & 21.979 & 26.022 & 18.954 \\
LEV & 8783 & 0.541 & 0.217 & 0.545 & 1.369 & 0.082 \\
PE & 8783 & 74.334 & 162.730 & 30.742 & 1039.414 & -238.198 \\
DUA & 8783 & 0.138 & 0.345 & 0.000 & 1.000 & 0.000 \\
AUD & 8783 & 0.070 & 0.255 & 0.000 & 1.000 & 0.000 \\
HE & 8783 & 0.220 & 0.414 & 0.000 & 1.000 & 0.000 \\
OP & 8783 & 0.055 & 0.227 & 0.000 & 1.000 & 0.000 \\
\hline
\end{tabular}

\subsection{Correlation Analysis}

Before performing correlation analysis and regression analysis on the sample data, a multicollinearity test is first performed on all variables to avoid affecting the test results and the stability of regression model. After multivariate collinearity tests were performed on the variables, based on the test results and the correlation index, the correlation between the explanatory variables selected by the model was not strong, there was no multicollinearity, the influence on the dependent variables was relatively independent, and the model design was reliable and stable. Whether or not the fair value FV is used in this correlation analysis is not significantly related to handling accruals, but in a further partial correlation analysis, it shows a significant positive correlation with the dependent variable and is consistent with expectations.

\subsection{Regression Result}

Because fair value involves a large number of judgments and assumptions during its use, its subjectivity is likely to have an adverse effect on the reliability of accounting information. The regression analysis results are shown in Table 3. The correlation coefficient between FV and DA was 0.021 , with a significance of 0.044 . It was significant at the 0.05 level and FV was significantly 
positively correlated with DA. It shows that fair value measurement is significantly positively correlated with control accruals, and the use of fair value measurement the accrued profit will increase, that is, fair value measurement is significantly negatively correlated with the reliability of accounting information. Management is likely to use fair value for profit manipulation, affect the disclosure of accounting information, and its use will reduce the reliability of accounting information. At this point, the analysis results are in line with expectations. The hypothesis of this study is verified, and the regression results of the remaining control variables are consistent with the foregoing and expected results.

Table 2. Correlation analysis

\begin{tabular}{|c|c|c|c|c|c|c|c|c|c|}
\hline & DA & FV & SIZE & LEV & PE & DUA & AUD & HE & OP \\
\hline DA & 1.000 & $-.024 * *$ & $-.170 * * *$ & $.137 * * *$ & $-0.019^{*}$ & $.054 * * *$ & $-.077 * * *$ & $-0.018^{*}$ & $176^{* * *}$ \\
\hline FV & $-0.020 *$ & 1.000 & $.190 * * *$ & 0.003 & $-.039 * * *$ & $-.039 * * *$ & $.149 * * *$ & -0.015 & $-.072 * * *$ \\
\hline SIZE & $-.156 * * *$ & $.161 * * *$ & 1.000 & $.182 * * *$ & $-.197 * * *$ & $-.105 * * *$ & $.399 * * *$ & $.286^{* * *}$ & $-.245^{* * *}$ \\
\hline LEV & $.064 * * *$ & $.022 * *$ & $.271 * * *$ & 1.000 & $-.080 * * *$ & $-.023^{* *}$ & $.023 * *$ & -0.005 & $.279 * * *$ \\
\hline PE & $-.063 * * *$ & $-.046 * * *$ & $-.261 * * *$ & $-.154 * * *$ & 1.000 & $.034 * * *$ & $-.073 * * *$ & $-.045 * * *$ & 0.009 \\
\hline DUA & $.051 * * *$ & $-.039 * * *$ & $-.106 * * *$ & $-.035 * * *$ & $.029 * * *$ & 1.000 & $-.046 * * *$ & $-.089 * * *$ & $.032 * * *$ \\
\hline AUD & $-.083 * * *$ & $.149 * * *$ & $.334 * * *$ & $.029 * * *$ & $-.131 * * *$ & $-.046 * * *$ & 1.000 & $.146^{* * *}$ & $-.056 * * *$ \\
\hline HE & $-.031 * * *$ & -0.015 & $.272 * * *$ & 0.012 & $-.064 * * *$ & $-.089 * * *$ & $.146 * * *$ & 1.000 & $-.080 * * *$ \\
\hline OP & $.128 * * *$ & $-.072 * * *$ & $-.224 * * *$ & $.174 * * *$ & $-.098 * * *$ & $.032 * * *$ & $-.056 * * *$ & $-.080 * * *$ & 1.000 \\
\hline
\end{tabular}

Note: The upper triangle is the Pearson correlation coefficient, and the lower triangle is the Spearman correlation coefficient. The above significance test is a two-tailed test;

Correlation was significant at 0.01 level; Correlation was significant at 0.05 level; Correlation was significant at 0.10 level (same below).

Table 3. Correlation analysis

\begin{tabular}{cccc}
\hline Variables & Coefficient & T-statistic & P \\
\hline FV & $0.021^{* *}$ & 2.016 & 0.044 \\
SIZE & $-0.184^{* * *}$ & -13.967 & 0.000 \\
LEV & $0.128^{* * *}$ & 11.361 & 0.000 \\
PE & $-0.045^{* * *}$ & -4.355 & 0.000 \\
DUA & $0.035^{* * *}$ & 3.511 & 0.000 \\
AUD & -0.011 & -1.010 & 0.313 \\
HE & $0.039^{* * *}$ & 3.672 & 0.000 \\
OP & $0.096^{* * *}$ & 8.722 & 0.000 \\
N & 8783 & & \\
Adjusted R2 & 0.127 & & \\
Intercept & 0.409 & & \\
\hline
\end{tabular}

\section{Conclusion}

The above analysis results show that the application of fair value will reduce the reliability of accounting information, that is, the study hypothesis has been verified, and further proves the negative impact of fair value measurement on the quality of accounting information. And from the perspective of controlled accruals, it provides a data support for the study of fair value.

\section{References}

[1]. D. Drum, A. Pernsteiner, and A. Reva, Journal of Accounting \& Organizational Change. Letters 13, 44-64 (2017).

[2]. F. Goo, H. Goo and G. Zhang, Accounting Research. Letters 3, 22-29 (2017).

[3]. F. M. Ramos and R. Calamari, Revisit de Administração FACES Journal. Letters 16, 86-101 (2017). 
[4]. G. D. Wang, Finance and Economics (Academic Edition). Letters 5, 170 (2016).

[5]. J. Wang, Accounting for China Township Enterprises. Letters 1, 70-72 (2016).

[6]. S. H. Wang, Z.Q. Liu and Y. Zhang, Audit Research. Letters 2, 48-56 (2017).

[7]. S. H. Yang, Auditing Research. Letters 2, 104-112 (2018). 